\title{
Questionable association between a monoamine oxidase A promoter polymorphism and sudden infant death syndrome
}

\author{
Michael Klintschar • Christian Heimbold
}

Received: 9 March 2010 /Accepted: 11 March 2010/Published online: 1 April 2010

(C) The Author(s) 2010. This article is published with open access at Springerlink.com

Sirs,

We have read with interest the article "Association of dopamine transporter and monoamine oxidase molecular polymorphisms with sudden infant death syndrome and stillbirth: new insights into the serotonin hypothesis" by Filonzi et al. in a recent edition of Neurogenetics [1]. The authors have presented a study on two polymorphisms, one of those a functional length polymorphism in the promoter region of the monoamineoxidase A (MAOA) gene, in 20 cases of sudden infant death syndrome (SIDS) and five cases of stillbirth compared to healthy controls. The main conclusion from the paper seems to be that MAOA allele 4R (with increased transcriptional activity) is significantly more common in SIDS than in controls.

There are, however, severe concerns that this conclusion could be incorrect:

1. The most problematic point of the study is that the authors obviously were not aware that MAOA is an Xchromosomal locus. They tested 25 cases, 13 of these male and 12 female, and - as can be deduced from Table 2 in this paper - are of the opinion that by doing so 50 alleles are included into the study. However, they tested only 37

\footnotetext{
M. Klintschar $(\bowtie)$

Institute of Legal Medicine, Hannover Medical School,

Hannover, Germany

e-mail: klintschar.michael@mh-hannover.de

C. Heimbold

Institute of Legal Medicine, University Göttingen,

Göttingen, Germany
}

alleles, as males have only one allele for this $\mathrm{X}$ chromosomal locus, whereas typing fewer alleles is bound to result in weaker statistical evidence.

2. There are also other less severe but still important problems: The case sample is extremely small and inhomogeneous. In fact, this study seems to repeat the results presented in a previous publication by the same authors [2] but for five cases of stillbirth that were added. From our point of view, it might be worth to discuss whether stillbirth and SIDS might have the same biological background, but it seems to be premature to pool these entities for a disease association study. In contrast, association studies in SIDS are normally conducted on case groups of 100 or more [3, 4].

Therefore, in order to check the results by Filonzi et al. in an independent study, we typed the MAOA locus using PCR with fluorescence-labeled primers and capillary electrophoresis in small cohorts of 22 male and 21 female SIDS cases and 20 male and 21 female controls.

In contrary to the findings of Filonzi et al., we found a however, statistically insignificant - trend towards a lower incidence of allele 4 in male, but not in female SIDS cases (Table 1).

We thus conclude that a potential association of SIDS and MAOA promoter polymorphism is worth to be further studied in a larger sample but that the conclusions drawn in the study by Filonzi et al. might very well be misleading. The X-chromosomal location of this polymorphism is most intriguing, as there is a male preponderance in SIDS and linkage to an X-chromosomal locus might be an explanation for this phenomenon [5]. 
Table 1 Alleles for the X-chromosomal MAOA promoter polymorphism in 22 male and 21 female SIDS victims (above) and 20 male and 21 female controls (below)

\begin{tabular}{lrlrl}
\hline Allele & Male & & Female \\
\hline SIDS & & & 0 & 0 \\
2 & 1 & 0.045 & 12 & 0.286 \\
3 & 12 & 0.545 & 0 & 0 \\
3,5 & 0 & 0 & 30 & 0.714 \\
4 & 8 & 0.364 & 0 & 0 \\
5 & 1 & 0.045 & 42 & \\
Number & 22 & & 0 & 0 \\
Controls & & & 16 & 0.381 \\
2 & 0 & 0 & 0 & 0 \\
3 & 7 & 0.350 & 26 & 0.619 \\
3,5 & 0 & 0 & 0 & 0 \\
4 & 13 & 0.650 & 42 & \\
5 & 0 & 0 & & \\
Number & 20 & & &
\end{tabular}

Open Access This article is distributed under the terms of the Creative Commons Attribution Noncommercial License which permits any noncommercial use, distribution, and reproduction in any medium, provided the original author(s) and source are credited.

\section{References}

1. Filonzi L, Magnani C, Lavezzi AM, Rindi G, Parmigiani S, Bevilacqua G, Matturri L, Marzano FN (2009) Association of dopamine transporter and monoamine oxidase molecular polymorphisms with sudden infant death syndrome and stillbirth: new insights into the serotonin hypothesis. Neurogenetics 10 (1):65-72

2. Nonnis Marzano F, Maldini M, Filonzi L, Lavezzi AM, Parmigiani S, Magnani C, Bevilacqua G, Matturri L (2008) Genes regulating the serotonin metabolic pathway in the brain stem and their role in the etiopathogenesis of the sudden infant death syndrome. Genomics 91(6):485-491

3. Poetsch M, Nottebaum BJ, Wingenfeld L, Frede S, Vennemann M, Bajanowski T (2010) Impact of sodium/proton exchanger 3 gene variants on sudden infant death syndrome. J Pediatr 156 (1):44-48

4. Klintschar M, Reichenpfader B (2008) Saternus KS (2008) A functional polymorphism in the tyrosine hydroxylase gene indicates a role of noradrenalinergic signaling in sudden infant death syndrome. J Pediatr 153(2):190-193

5. Mage DT, Donner M (2004) The X-linkage hypotheses for SIDS and the male excess in infant mortality. Med Hypotheses 62 (4):564-567 